\title{
PSA Decline Greater than 75 Percent
}

National Cancer Institute

\section{Source}

National Cancer Institute. PSA Decline Greater than 75 Percent. NCI Thesaurus. Code C153409.

A finding indicating that the blood concentration of prostate specific antigen in a subject's sample has decreased by 75 percent or more over the value recorded for a previous sample from that subject. 